\title{
POR UM DIÁLOGO UNIFORME ENTRE A UNIÃO EUROPEIA, ESTADOS UNIDOS E BRASIL: UMA ANÁLISE COMPARATIVA DAS NORMAS CONFLITUAIS EM MATÉRIA CONTRATUAL NOS TRATADOS INTERNACIONAIS
}

\author{
IN PURSUIT OF AN UNIFORM DIALOGUE BETWEEN THE EUROPEAN \\ UNION, UNITED STATES AND BRAZIL: A COMPARATIVE ANALYSIS OF \\ THE CONFLICTUAL CONTRACT NORMS IN INTERNATIONAL TREATIES
}

\author{
Tânia Lobo Muniz' \\ Victor Hugo Alcalde do Nascimento ${ }^{2}$
}

\begin{abstract}
RESUMO - O Direito funda-se no constante diálogo, seja no âmbito doméstico dos Estados, ou na sua esfera internacional. Nesta, vige o crescente movimento em prol da unificação ou harmonização de setores previamente determinados do Direito Privado. Um destes é o conflito de leis em matéria contratual, que é enfrentado, distintamente, por União Europeia, Estados Unidos e Brasil. Perante o Direito Comparado, todos estes entes enfrentam igual problema: como solver os conflitos de leis em matéria contratual, embora se tratam de ordenamentos jurídicos orientados por valores, história e cultura distintos. Às características dos ordenamentos jurídicos encontram-se presentes três famílias jurídicas, agrupadas como Direito romanístico-francês, Direito germânico e Common-Law; em todos há diferentes tratamentos à matéria de conflitos de leis em sede de contratos. O diálogo entre estas três famílias jurídicas, representadas por União Europeia, Estados Unidos e Brasil só é possível através de tratados internacionais, que devem, ao serem elaborados respeitar as diferenças entre os sistemas jurídicos em questão. Entre unificar e harmonizar o Direito deve-se ater os valores envolvidos, notadamente o da justiça vez que, a unificação das instituições jurídicas, muitas vezes, força a adoção de medidas que são incompatíveis com algum ordenamento jurídico. Em sede de conflitos de leis em matéria contratual, salienta-se que, oportunizar a ampla autonomia da vontade, para que as partes elejam o Direito aplicável não demonstra respeito ao valor justiça, tampouco restringi-la excessivamente. Há espécies contratuais que comportam a autonomia da vontade, a autonomia conflitual tutela de forma irrestrita, e outras que merecem maior zelo estatal ou internacional, escolhendo-se, portanto,

\footnotetext{
${ }^{1}$ Doutora em Direito pela PUC/SP (Pontifícia Universidade Católica de São Paulo). Professora orientadora do Programa de Pós-Graduação strictu senso - mestrado em Direito Negocial da UEL. Endereço profissional: Rodovia Celso Garcia Cid, Pr 445 Km 380, Campus Universitário, Centro de Estudos Sociais Aplicados, Mestrado em Direito, Cx. Postal 6001, CEP 86051-980, Londrina - PR, Fone: (43) 3371-4000, Fax: (43)3328-4440. E-mail: lobomuniz@gmail.com.

${ }^{2}$ Mestrando em Direito Negocial pela Universidade Estadual de Londrina. Advogado. Endereço profissional: Rodovia Celso Garcia Cid, $\operatorname{Pr} 445 \mathrm{Km} \mathrm{380,} \mathrm{Campus} \mathrm{Universitário,} \mathrm{Centro} \mathrm{de}$ Estudos Sociais Aplicados, Mestrado em Direito, Cx. Postal 6001, CEP 86051-980, Londrina PR, Fone: (43) 3371-4000, Fax: (43)3328-4440. E-mail: victoralcalde@sercomtel.com.br.
} 
outros pontos de conexão como o local da celebração ou o local de execução do negócio jurídico.

PALAVRAS-CHAVE - Conflito normativo. Direito Contratual. Direito Internacional. Tratados Internacionais.

ABSTRACT - The Law settles itself in the permanent dialogue, as it happens in the municipal sphere of the States, or in the international dimension. In this dimension, there is a progressive movement dedicated to the unification or harmonization of predetermined sectors of Private Law. One of those sectors is the conflict of laws in contracts, which is faced differently by European Union, the United Sates and Brazil. Before the Comparative Law all of them face the same problem: how to solve the conflict of laws in contractual issues, although they are juridical systems oriented by different values, history and culture. In terms of the characteristics of the juridical systems there are founded three legal families, grouped as Romanistic-French Law, Germanic Law and common Law; in all of them there are different treatments of the conflicts of laws in contractual issues. The dialogue between the three legal families, represented by European Union, the United Sates and Brazil is possible only through international treaties, which should be elaborated in respect of the differences of the legal systems. Between unify and harmonize the Law it should be in conformance with certain values, mainly justice, since the unification of the juridical institutions, in many times, force the adoption of incompatible measures in relation to a legal system. In the conflicts of laws in contractual issues it is important to mention that to give an ample party autonomy, which allows the parties to elect the Law applied may not represent the respect to justice, neither restrict the party autonomy excessively. There are species of contracts which are supported by an ample party autonomy, a conflictual autonomy and others which demand a special State or international care, electing, therefore, other connecting factors as the place of the celebration and the place of performance.

KEYWORDS - Contract Law. Conflict Between Norms. International Law. International Treaties

\section{INTRODUÇÃO}

Reputa-se a Cícero o seguinte dístico: "há duas formas de se disputar sobre uma coisa, uma é pelo debate, a outra pela força" (apud GROTIUS, 2005, p. 134 - tradução livre). Suas palavras demonstram qual a relevância que o debate, o diálogo possui e situa-o em extremo oposto ao da força, da guerra, do conflito armado, que, aliás, é repudiado pelo Direito. O debate funda

\footnotetext{
${ }^{3}[\ldots]$ there are two Ways of disputing Things, one by Debate, the other by Force (CICERO apud GROTIUS, 2005, p. 134).
} 
- Direito, quer seja manifestado por linguagem escrita, quer pela oralidade, concretiza-se na prestação jurisdicional e no esforço de uma consciência jurídica universal na busca de preceitos normativos harmônicos ou uniformes na persecução da solução de problemas comuns.

Na seara internacional o debate jurídico torna-se possível por meio de uma linguagem que manifesta conceitos distintos, pois, originam-se de indivíduos e Estados diferentes, provenientes de idiomas, culturas e situações econômicas díspares.

Assim é o cenário no qual versará a presente análise: o discurso jurídico possível entre União Européia, Estados Unidos e Brasil em matéria de conflitos de leis em contratos.

Muitas são as diferenças entre os membros do recorte geográfico traçado. A Europa, o velho continente, abriga diversos Estados, que, embora fronteiriços, comungam de histórias, culturas, ordenamentos jurídicos distintos. O mesmo aplica-se aos Estados Unidos, que, historicamente, compõem-se da associação de Estados-membros, cada qual com história, manifestações culturais e ordenamentos jurídicos (em determinadas matérias) díspares. $\mathrm{O}$ sistema normativo brasileiro caracteriza-se por mesclar conceitos do Direito Romano e do Direito germânico, ambos presentes no Continente europeu.

Entretanto, embora as diferenças sejam consideráveis, juntos, consubstanciam importante dimensão geográfica, na qual há relevante acúmulo de riquezas, influência política em sede de relações internacionais e capacidade produtiva.

O comércio une estas regiões e o instituto jurídico comum para tais transações é o contrato. Neste sentido, por meio de ações políticas, fundadas no debate entre os Estados envolvidos, busca-se a uniformidade ou harmonização dos preceitos normativos em matéria contratual, na persecução clara de facilitar, aprimorar o intercâmbio transnacional entre aqueles países.

O presente artigo organiza-se segundo a concepção trialista do mundo jurídico de Werner Goldschmidt, e, portanto, divide-se em três dimensões, a saber: a sociológica, a normológica e a dikelógica. Trata-se de concepção que possibilita uma análise completa do Direito, orientada não somente no estudo 
agnóstico de preceitos normativos, mas dos fatos jurídicos que deflagram o processo normativo, ou que clamam por tutela, as normas propriamente ditas, e o seu fim, o valor segundo o qual existem, a justiça.

\section{DA DIMENSÃO SOCIOLÓGICA}

O trialismo de Werner Goldschmidt traduz-se na construção do Direito como a conjugação das dimensões sociológica, que se ocupa dos fatos, uma dimensão dikélogica, preocupada com a justiça e outra dimensão normológica, destinada às normas jurídicas. Trata-se de uma teoria erguida sob a concepção tridimensional do mundo jurídico, vez que, "a diferença entre concepção e teoria reside em que a primeira marca os grandes pilares do direito, enquanto que a segunda inquire e determina sobre o conteúdo dos três elementos" ${ }^{\prime 4}$ (ZANETTI, 2009, p. XXVI - tradução livre)

Os fatos, residentes da dimensão sociológica, a serem explanados neste capítulo, são, também, "matéria de estudo de outras ciências como, por exemplo, a médica, a referida à educação, a antropologia, etc" ${ }^{5}$ (ZANETTI, 2009, p. XXVI - tradução livre), entretanto, importa à ciência jurídica, apenas "aqueles que podem ser aferidos do ponto de vista da justiça"6 (ZANETTI, 2009, p. XXVI - tradução livre).

Contudo, é certo que, assim como o Direito, a justiça é, também, dependente de conceituação e, pois são palavras que expressam algo mutável, conforme aquele que o utiliza dentro de determinado contexto. Entretanto, todos os conceitos de justiça já formulados, desde a atávica reciprocidade, fundada no dar-te-ei o que tu me deres, do utilitarismo ${ }^{7}$, do liberalismo e do libertarismo, todas servem como meio avaliativo do fato.

\footnotetext{
${ }^{4}$ La diferencia entre concepción y teoría estriba en que la primera marca los grandes pilares del derecho mientras la segunda inquiere y precisa sobre el contenido de los tres elementos (ZANETTI, 2009, p. XXVII).

${ }^{5}$ [...] materia de estudio de otras ciencias como, por ejemplo, la médica, la referida a la educación, la antropológica, etc. (ZANETTI, 2009, p. XXVI).

${ }^{6}$ [...] aquellos que pueden ser estimados desde el punto de vista de la justicia (ZANETTI, 2009, p. XXVI).

${ }^{7}$ Utilitarismo, segundo o Black's Law Dictionary trata-se da "doutrina filosófica e econômica cuja melhor política social é aquela que faz o bem maior para o maior número de pessoas"
} 
Os fatos não serão possíveis de aferição senão segundo a justiça fundada em determinada concepção assim como não serão aferíveis considerando-se outra concepção de justiça. O que mudará o grau de justo que um conceito atribuirá a determinado fato.

No plano geográfico predeterminado - Europa, Estados Unidos e Brasil - o intercâmbio entre os Estados que o compõem é inevitável, por vezes devido ao comércio internacional, fundado na abertura de fronteiras às mercadorias e serviços, outras pelo contato cultural que se constrói, fruto de migrações. Entretanto, nestes Estados há a vigência de distintos ordenamentos jurídicos, com preceitos costumeiros ou normativos que impedem ou impossibilitam a consecução de muitos negócios jurídicos. É dizer que, apesar da abertura fronteiriça ao capital, pessoas, serviços e mercadorias, em cada país em que ingressarem submeter-se-ão a um ordenamento distinto, nem sempre semelhantes.

Salienta-se que, dada essa pluralidade referida, há quem busque, mediante análise pormenorizada, eleger, em qual ordenamento deseja ter seu negócio jurídico vinculado. Esta escolha é fruto de uma autonomia da vontade, que, entretanto, por vezes, quando manipulada com intuitos escusos, leva a frauda à lei. Vê-se, portanto, um limite tênue entre a autonomia da vontade que possibilita por qual legislação contrair obrigações e direitos, e a fraude à lei, a escolha da legislação aplicável mediante procedimentos ilícitos.

Henry S. Maine manifesta-se que "o movimento das sociedades progressistas tem, até agora, sido um movimento do status ao contrato"8 (apud ZWEIGERT, KÖTZ, 1998, p. 325 - tradução livre). Este dístico expõe o avanço das sociedades, em prol da sua emancipação. Ademais, por "séculos os direitos e deveres dos indivíduos eram determinados pelo seu nascimento, sua

(2009, p. 1686 - tradução livre; transcrição: "the philosophical and economic doctrine that the best social policy is that which does the most good for the greatest number of people"). É dizer, é "uma teoria ética que julga o justo e o injusto das ações conforme o prazer que eles criam ou a dor a afligem e recomenda qualquer ação que crie o melhor para o maior número de pessoas" (2009, p. 1686 - tradução livre - transcrição: "an ethical theory that judges the rightness or wrongness of actions according to the pleasure they create or the pain they inflict and recommends whatever action creates the greatest good for the greatest number of people").

8 [...] the movement of the progressive societies has hitherto been a movement from Status to Contract (MAINE apud ZWEIGERT, KÖTZ, 1998, p. 325). 
família, sua pele, sua tribo, seu status, sua associação ou sua posição como vassalo a um superior feudal ou com um servo de um dono de terras" ${ }^{\prime 9}$ (ZWEIGERT, KÖTZ, 1998, p. 325 - tradução livre). O contrato é um marco à liberdade e igualdade na história das conquistas dos seres humanos.

Estes institutos jurídicos gozam de paridade vinculante com os atos normativos, promulgados ou outorgados, pelo Estado.

\subsection{DO DIREITO COMPARADO}

Inserido na dimensão sociológica está o Direito Comparado que apesar de intitular-se Direito, não se trata de um conjunto de preceitos normativos, mas sim a uma técnica, que como verá, versa sobre problemas.

O Direito Comparado funda-se na "construção de relações de semelhança ou dessemelhança entre diferentes questões de fato"10 (JANSEN, 2008 , p. 310 - tradução livre), que, uma vez escolhidas pelo interprete, são postas lado a lado, traçando-lhes as igualdades e distinções segundo um tertium comparationis, uma "relação triádica entre dois objetos e determinada qualidade"

Este ramo da disciplina jurídica não se funda no excesso de regras metodológicas. O Direito Comparado é distinto, trata-se de uma disciplina recente, cuja origem, assim entendida, ou como versada por alguns autores, na sua "belle époque", deu-se no início do século XX, em 1900, precisamente, no Congresso de Paris, destinado à matéria.

Muitas são as razões elencadas para a carência de metodologia no Direito Comparado. Konrad Zweigert e Hein Kötz asseveram que, uma das razões é o fato de que "comparatistas de todo o mundo estão perfeitamente despreocupados sobre as suas metodologias e vêem-se em um estágio

\footnotetext{
${ }^{9}$ For centuries an individual's right and duties were determined by his birth, his family, his skin, his tribe, his status, his guild or his position as vassal to a feudal superior or as a serf to a landowner (ZWEIGERT, KÖTZ, 1998, p. 325).

${ }_{10}$ [...] construction of relations of similarity or dissimilarity between different matters of fact (JANSEN, 2008, p. 310).
} 
experimental"11 (1998, p. 33 - tradução livre). Os autores aduzem, ademais, que "tem tido poucos escritos sistemáticos acerca dos métodos do direito comparado"12 (1998, p. 33 - tradução livre). Embora poucos, esses esforços não são inexistentes, e, neste artigo utilizar-se-á do método ou doutrina da comparação funcional.

Korand Zweigert e Hein Kötz advogam que "o princípio metodológico básico de todo direito comparado é aquela da funcionalidade"13 (1998, p. 34 tradução livre). Esta ilação, todavia, necessita de maiores explanações, vez que o termo funcionalidade induz a inúmeros conceitos. Neste sentido, manifesta-se Ralf Michaels aduzindo que "o método funcional é uma tripla impropriedade"14 (2008, p. 342 - tradução livre).

A busca pela comparação funcional, embora possua caráter científico, requer outros conhecimentos além do jurídico. Ernst Rabel assevera que:

\begin{abstract}
Ideias de todos os tipos têm seus efeitos, por isso não é somente o feudalismo, liberalismo e socialismo que produzem diferentes tipos de direito; instituições jurídicas uma vez adotadas podem ter conseqüências lógicas; e não menos importante é o esforço por um ideal jurídico ou político. Tudo nos campos social, econômico e jurídico interagem. O direito de todo povo desenvolvido está em constante movimento, e toda a figura caleidoscópica é uma que ninguém consegue ver claramente ${ }^{15}$ (apud ZWEIGERT, KÖTZ, 1998, p. 36 - tradução livre).
\end{abstract}

No espaço geográfico delimitado - União Européia, como ente representante do continente europeu, os Estados Unidos, como representante da América do Norte e o Brasil - em sede de Direito Comparado, é mister

\footnotetext{
${ }^{11}[\ldots]$ comparatists all over the world are perfectly unembarrassed about their methodology, and see themselves as being at the experimental stage (ZWEIGERT, KÖTZ, 1998, p. 33).

12 [...] there has been very little systematic writing about the methods of comparative law (ZWEIGERT, KÖTZ, 1998, p. 33).

${ }^{13}$ The basic methodological principle of all comparative law is that of functionality (ZWEIGERT, KÖTZ, 1998, p. 34).

${ }_{15}^{14}[\ldots]$ the functional method is a triple misnomer (MICHAELS, 2008, p. 342).

${ }^{15}$ Ideas of every kind have their effect, for it is not just feudalism, liberalism and socialism which produce different types of law; legal institutions once adopted may have logical consequences; and not least important is the striving for a political or legal ideal. Everything in the social, economic and legal fields interacts. The law of every developed people is in constant motion, and the whole kaleidoscopic picture is one which no one has ever clearly seen (RABEL apud ZWEIGERT, KÖTZ, 1998, p. 36).
} 
caracterizá-los segundo famílias, conjuntos de Estados, notadamente, de seus ordenamentos jurídicos segundo semelhanças comuns.

O agrupamento em famílias, entretanto, organiza-se conforme as características comuns mediante um ou vários tertia comparationis. Nestes termos, por exemplo, o Direito Comparado tem-se manifestado sob auspícios exclusivos do Direito Privado, logo, as famílias são divididas considerando-se o Direito Privado. Ao empregar-se o termo família da common Law, por exemplo, considera-se apenas o Direito Privado dos Estados que a compõe.

$\mathrm{Na}$ teoria das famílias jurídicas, é importante destacar mencionar o trabalho de René David, na sua obra intitulada Les grands système de droit contemporain, cuja primeira edição deu-se em 1964. Nesta obra, ressaltam-se suas mudanças, atestadas por Bénédicte Fauvarque-Cosson. Este aduz que aquele, no decorrer histórico, observando as mudanças nas instituições jurídicas, modificou diversas vezes seu trabalho. Na primeira edição havia a classificação perante cinco famílias: sistema ocidental, sistema socialista, Direito Islâmico, Direito Chinês e Direito Hindu. Posteriormente, "David, levemente, modificou suas categorias por, primeiramente, distinguir três famílias jurídicas: a família Romano-Germânico, a common law, e a (agora falecida) família socialista" ${ }^{\text {"16 }}$ (FAUVARQUE-COSSON, 2008, p. 46 - tradução livre).

$\mathrm{Na}$ última edição, de 2002, Bénedicte Fauvarque-Cosson aduz que David, com apoio do co-autor Camille Jauffret-Spinosi,

\begin{abstract}
distingue três famílias jurídicas: a família Romano-Germânica, a família common law, e a família russa (que não mais pode ser classificada com a família socialista) e acrescenta uma quarta parte intitulada "outras concepções de ordem social e do direito", que inclui 0 direito muçulmano, indiano, chinês, japonês, e africano ${ }^{17}$ (2008, p. 46 - tradução livre).
\end{abstract}

${ }^{16}$ [...] David slightly modified his categories by first distinguishing three legal families: the Romano-Germanic family, the common law, and the (now dismantled) socialist family (FAUVARQUE-COSSON, 2008, p. 46).

17 [...] distinguishes three legal families: the Romanistic-German family, the common law family and the Russian family (which can no longer be classified as the socialist family) and adds a fourth part entitled "other conceptions of the social order and of the law", which includes Muslim, Indian, Chinese, Japanese, and African law (FAUVARQUE-COSSON, 2008, p. 46). 
A obra de René David, é importante salientar, considera como tertia comparationis a técnica jurídica, notadamente o papel desempenhado pelas fontes jurídicas e a concepção destas, assim como ideologias envolvidas na construção dos ordenamentos jurídicos.

Há outras classificações que demonstram maior coerência e evitam imprecisões, como a que é adotada na obra de Konrad Zweigert e Hein Kötz, elaborada segundo Arminjon, Nolde e Wolff. Nestes, a divisão por famílias prescinde do uso, como tertium comparationis, da substância, "prestando devida atenção à originalidade, derivação, e elementos comuns, e sem referências a fatores extrínsecos com geografia ou raça"18 (ZWEIGERT, KÖTZ, 1998, p. 64 - tradução livre). A classificação dos autores dá-se em sete famílias, a saber: a francesa, a alemã, a escandinava, a inglesa, a russa, a islâmica, e a hindu.

Konrad Zweigert e Hein Kötz, inspirados na doutrina de Arminjon, Nolde e Wolff, fundada na substância dos ordenamentos jurídicos, elaboram pequena alteração, classificando em família romanística, família germânica, família nórdica, família do common law, e seções dedicadas ao Direito chinês, ao japonês, ao islâmico e ao hindu. Esta é a organização adotada para a explanação da matéria delimitada neste artigo.

Na dimensão geográfica determinada, há emprego de várias famílias: no âmbito da União Europeia há as famílias do Direito romanístico, representada por Estados inspirados em fontes do Direito Romano, notadamente, a França; há a família germânica, composta pela Alemanha e Áustria, e, há o common law, identificado pelo Reino Unido. Neste espaço, há o Direito Comunitário, que não se pode indicar nenhuma família, e, que abriga aqueles Estados detentores de grandes distinções em seus ordenamentos jurídicos. Apesar destas diferenças, a União Europeia consegue harmonizar e unificar várias matérias jurídicas, por meio de tratados entre seus membros, ou suas normas próprias como os regulamentos e as diretivas.

\footnotetext{
${ }^{18}$ [...] paying due heed to originality, derivation, and common elements, and without any reference to extrinsic factors such as geography or race (ZWEIGERT, KÖTZ, 1998, p. 64).
} 
No âmbito europeu, a família romanística do Direito, representada, notadamente pela França, a partir da promulgação do Código Civil de 1804, verdadeiro modelo inspirador para outros Estados compreendidos nesta família. Este instrumento jurídico é fruto do "espírito da Revolução Francesa que procurou erradicar as instituições feudais do passado e em implantar no lugar os valores do direito natural de propriedade, liberdade de contratar, família e herança familiar"19 (ZWEIGERT, KÖTZ, 1998, p. 74 - tradução livre).

A família jurídica romanística, como a própria denominação denota, é muito influenciada pelo Direito Romano. O código civil francês, ademais, é resultado de "um longo desenvolvimento histórico, e a maior parte deste é uma feliz junção de instituições jurídicas do droit écrit do sul, influenciado pelo Direito Romano, e o droit coutumier do norte, influenciado pelo germânicofranco direito costumeiro"20 (ZWEIGERT, KÖTZ, 1998, p. 75 - tradução livre). A parcela de direito costumeiro, encontrada no sul da França no século XII, não excluía no todo o Direito Romano. Ao contrário, "algumas partes do direito, por exemplo, dos contratos, eram inadequadamente regulados pelos costumes e, portanto, advogados prontamente faziam recurso do melhor desenvolvido e mais refinado Direito Romano"21 (ZWEIGERT, KÖTZ, 1998, p. 76 - tradução livre).

O Código Civil francês, exemplar da família romano-francesa do Direito, influenciou outros Estados que compõem a dimensão geográfica determinada, a saber, Itália, Espanha, assim como, na América Latina, o Brasil e Argentina. Estes estados mencionados, portanto, compõem a família jurídica em apreço.

A família jurídica Germânica é caracterizada, em oposição à romanofrancesa, pelo tardio contato com o Direito Romano, vez que, "quando a Alemanha entrou em contato com o Direito Romano era relativamente tarde -

\footnotetext{
${ }^{19}[\ldots]$ spirit of the France Revolution which sought to eradicate the feudal institutions of the past and to implant in their place the natural law values of property, freedom of contract, family and family inheritance (ZWEIGERT, KÖTZ, 1998, p. 74).

${ }^{20}$ [...] a long historical development, and most of it is a felicitous blend of traditional legal institutions from the droit écrit of the South, influenced by Roman Law, and the droit coutummier of the North, influenced by the Germanic-Frankish customary law (ZWEIGERT, KÖTZ, 1998, p. 75).

${ }^{21}$ Some parts of the law, for example contract law, were inadequately regulated by the coutumes and therefore lawyers readily had recourse to the better developed and more refined Roman Law (ZWEIGERT, KÖTZ, 1998, p. 76).
} 
não antes de meados do século XV"22 (ZWEIGERT, KÖTZ, 1998, p. 133 tradução livre). A concepção da codificação do Direito Alemão, ademais, em 1814, trouxe inúmeros debates quanto à sua necessidade, advogados favoravelmente por Thibaut e contestado por Friedrich Karl von Savigny.

O BGB, Bürgerlichen gesetzbuchs, o código civil alemão é fruto de uma escola pandectista alemão, dada a inserção e estudo do Direito Romano nas instituições de ensino. Para esta escola o "sistema jurídico era uma ordem fechada de instituições, ideias e princípios desenvolvidos do Direito Romano: alguém teria somente que aplicar métodos lógicos ou científicos no intuito de encontrar a solução"23 (ZWEIGERT, KÖTZ, 1998, p. 140 - tradução livre) para o litígio apresentado. A junção dos preceitos dessa escola às normas dos vários Direitos que vigiam na Alemanha nasce o BGB.

$\mathrm{Na}$ família germânica do Direito residem os Direitos Austríaco e Suíço, embora a legislação de Direito privado destes seja mais clara em linguagem e sejam desprovidos, ao contrário do BGB, de uma lei de introdução.

A última família jurídica abrangida na dimensão geográfica traçada é o common law. Nesta a influência do Direito Romano é periférica, o que o caracteriza sua origem é a centralização do Poder Judiciário e a unificação de Direitos regionais de filosofia feudal. Esta família compõe-se de normas estatuídas por um Poder Legislativo, assim como normas fruto de precedentes do Judiciário.

Os atos normativos estatuídos pelo Poder Legislativo denominam-se Atos do Parlamento (Acts of Parliament), comumente de statutes e no coletivo como Statute Law. Estes institutos jurídicos tiveram origem na "emissão da Magna Carta em 1225 no reinado de Henry III, e um grande volume é agora acrescido todo ano"24 (GELDART, 1995, p. 2 - tradução livre). Os estatutos são promulgados pelo Parlamento britânico que, em sua maior característica,

\footnotetext{
${ }^{22}$ When Germany came in contact with Roman Law it was relatively late - not before the middle of the fifteenth century (ZWEIGERT, KÖTZ, 1998, p. 133).

${ }^{23}[\ldots .$.$] legal system was a closed order of institutions, ideas, and principles developed from the$ Roman law: one only had to apply logical or scientific methods in order to reach the solution (ZWEIGERT, KÖTZ, 1998, p. 140).

${ }^{24}$ [...] reissue of Magna Carta in 1225 in the reign of Henry III, and a large volume is now added every year (GELDART, 1995, p. 2).
} 
desconhece limites; pode disciplinar qualquer matéria. Há, entretanto, "limitações práticas sobre o poder do Parlamento, e em particular é sem dúvida desejável que desde a entrada do Reino Unido nas Comunidades Europeia em 1973 que a legislação parlamentar deva conformar"25 (GELDART, 1995, p. 4 tradução livre).

A competência supra-estatal conferida à Comunidade Europeia, todavia, não fere a soberania ilimitada do Parlamento Britânico, vez que este Estado sempre poderá eximir-se das obrigações do bloco europeu e dele sair.

Dos Atos do Parlamento ressalta-se, ainda, que são de observância compulsória, não podendo ser seu cumprimento escusado por qualquer magistrado. São promulgados pelo Parlamento, conferem-no a chancela Real e, "onde Statute Law e Common Law colidem, é aquele que prevalece" (GELDART, 1995, p. 3 - tradução livre).

O Common Law compõe a outra parte dos ordenamentos jurídicos dos Estados que compõem esta família. Esta, embora seja versada por muitos autores como não escrita, é por sua forma escrita que é possível o contato, logo, todo o common law é escrito. Entre estes se encontram as decisões reportadas que

Desde o reinado de Edward I há tido advogados que fizeram como atividade reportar as discussões na corte e os julgamentos dados em casos que tivessem interesse jurídico. O mais antigo destes são os Year Books (anuários). Eles são reportes de casos feitos por reportadores anônimos do tempo de Edward I ao de Henry VIII ${ }^{26}$ (GELDART, 1995, p. 6 - tradução livre).

Os reportes dos precedentes jurisdicionais são elaborados e publicados até os presentes dias. Este sistema é semelhante ao outro Estado, compreendido na presente delimitação geográfica, os Estados Unidos. Neste,

\footnotetext{
${ }^{25}$ [...] practical limitations upon the Power of Parliament, and in particular it is doubtless highly desirable since the United Kingdom's entry to the European Communities in 1973 that parliamentary legislation should accord" (GELDART, 1995, p. 4).

${ }^{26}$ Ever since the reign of Edward I there have been lawyers Who have made it their business to report the discussions in court and the judgments given in cases which seemed of legal interest. The earliest of these reports are the Year-Books. They are reports of cases made by anonymous reporters from time of Edward I to that of Henry III (GELDART, 1995, p. 6).
} 
há a mesma dualidade de normas primeiras, vez que fora influenciado, economicamente e culturalmente pelo Reino Unido.

Na dimensão geográfica delimitada, vislumbra-se a presença das três famílias jurídicas acima citadas: a família romano-francesa, a família germânica e a família do common law. Dentre estes vigem inúmeras diferenças, que se manifestam na legislação contratual (que versa este artigo), assim como, nas questões conexas a este como a capacidade, requisitos formais e cumprimento das obrigações contraídas, por exemplo. Se há um diálogo entre os membros integrantes destas famílias, este dá-se por intermédio de línguas e linguagens distintas. A indagação ora proposta é, em matéria de conflito de leis, num ambiente onde o diálogo entre estes entes é inevitável, como no Direito Internacional Privado, é possível um diálogo comum?

\section{DA DIMENSÃO NORMOLÓGICA}

A dimensão normológica, no contexto das lições de Werner Goldschmidt, ocupa-se das normas jurídicas e dos ordenamentos aos quais integram. É fruto do contato entre as outras dimensões, vez que:

do diálogo entre a realidade e o valor surge a norma, a que em seu tipo legal enfoca dados proporcionados pela dimensão sociológica repartições e distribuições (fatos, conflitos, problemas, acordos) - e na consequência jurídica a solução "aconselhada" pela justiça (dimensão dikelógica) ${ }^{27}$ (ZANETTI, 2009, p. XXVII - tradução livre).

No âmbito contratual, na expectativa do diálogo ora proposto, viu-se no capítulo antecedente as diferenças entre os entes postos no debate fundado na expectativa de uma tratamento equânime em matéria de conflitos de leis em seara contratual internacional. Observaram-se as diferenças funcionais, frutos dos fatos, dada a diversidade cultural, econômica e ideológica dos Estados. Abaixo, analisar-se-ão as diferenças funcionais dos institutos jurídicos que

\footnotetext{
${ }^{27}$ Del diálogo entre la realidad y el valor surge la norma, la que en su tipo legal enfoca los datos suministrados por la dimensión sociológica - repartos y distribuciones (hechos, conflictos, problemas, acuerdos) - y en la consecuencia jurídica la solución "aconsejada" por la justicia (dimensión dikelógica) (ZANETTI, 2009, p. XXVII).
} 
disciplinam essa matéria, logo, adota-se como tertium comparationis funcional o modo como os Estados elencados resolvem o problema dos conflitos de leis em sede de contratos internacionais.

O elo unificador dos contratos internacionais a um Direito pleiteado pelas partes contraentes funda-se no estudo do Direito Internacional Privado, notadamente no elemento de conexão da norma conflitual daquele Direito. Este se trata de "um termo empregado para descrever a palavra ou palavras em uma norma de referência que indique o local do qual o direito possa ser utilizado para decidir a questão"28 (SYMEONIDES, HAY, BORCHERS, 2010, p. 146 - tradução livre). Esta parte da norma conflitual aponta qual o Direito aplicável, portanto.

O elemento de conexão figura como uma característica positiva do consequente da norma conflitual de Direito Internacional. O tipo legal, desta norma, que antecede aquele, prescreve e descreve uma conduta, que, vez realizada, é solvida pelo elemento de conexão de seu consequente jurídico. Este apenas indica qual o Direito aplicável a uma questão, envolvendo um elemento estrangeiro, e sub judice.

Os elementos de conexão, também denominados de pontos de conexão, "contêm a indicação nominativa do Direito aplicável mediante uma expressão variável, a qual se individualiza em atenção às particularidades do caso dado, as quais aquela enfoca"29 (GOLDSCHMIDT, 2009, p. 204 - tradução livre). Isso deve-se ao corolário de que o "Direito Internacional Privado, qualquer que seja seu propósito principal, não tem conteúdo material”30 (LIPSTEIN, 1981, p. 2 tradução livre). Suas normas, através do ponto de conexão, indicará o Direito, cujo conteúdo material é disposto para solver a questão trazida.

Há vários pontos de conexão no Direito Internacional Privado. Kurt Lipstein elenca-os:

\footnotetext{
${ }^{28}[\ldots]$ a term employed to describe the Word or words in a rule of reference which indicate the place whose law may be used to decide the issue (SYMEONIDES, HAY, BORCHERS, 2010, p. 146).

${ }^{29}[. .$.$] contienen la indicación del Derecho aplicable mediante una expresión variable, la cual se$ individualiza en atención a las particularidades del caso dado, las cuales aquélla enfoca (GOLDSCHMIDT, 2009, p. 204).

30 Private International Law, whatever its underlying purpose, has no material content (LIPSTEIN, 1981, p. 2).
} 
Nacionalidade, domicílio, residência, residência comum, residência habitual, local da contratação, local do cumprimento, local da situação do objeto, a intenção das partes, o centro de gravidade de uma relação, o local onde uma negociação é concluída e a localidade do tribunal apontada para a disputa ${ }^{31}$ (1981, p. 94 - tradução livre).

Dentre os pontos de conexão pode-se acrescer ao rol as expressões the most significant relationship (a relação mais significativa) ou a doutrina da análise de interesses, idealizada por Breinard Currie, ambos frutos da doutrina do Direito norte-americano. Neste sentido, Symeon Symeonides, Patrick J. Borchers e Peter Hay aduzem que "enquanto o Restatement (segundo) retém a qualificação conforme a matéria, chama a aplicação, na maioria dos casos, do direito do local com a "mais significativa relação" ao "caso particular"”32 (2010, p. 148 - tradução livre).

Os pontos de conexão podem classificar-se conforme o objeto de referência, ou seja, os indivíduos, direitos reais ou uma situação. Podem ser pontos de conexão pessoais, é dizer, "contemplar qualidades abstratas dos homens (por exemplo, a nacionalidade, o domicílio, a residência, a vinculação a um país por meio da prestação de serviços, etc)"33 (GOLDSCHMIDT, 2009, p. 204 - tradução livre). Serão, todavia, reais quando "referirem a objetos (como, por exemplo, a situação de imóveis e de móveis, o lugar de matrícula de um barco, uma aeronave, um automóvel, a propriedade intelectual, etc) ${ }^{\text {"34 }}$ (GOLDSCHMIDT, 2009, p. 204 - tradução livre). Os demais pontos de conexão, versam sobre situações, "acontecimentos (como, por exemplo, o lugar da celebração ou do cumprimento de um contrato, porto de saída ou de

\footnotetext{
${ }^{31}$ Nationality, domicile, residence, ordinary residence, habitual residence, place of contracting, place of performance, the place of the situation of the object, the intention of the parties, the centre of a relationship, the place where a transaction is concluded and the locality of the court seized of the dispute (LIPSTEIN, 1981, p. 94).

32 [...] while the Restatement (Second) retains subject matter characterization, it calls for the application, in most cases, of the law of the place with the "most significant relationship" to the "particular case" (SYMEONIDES, HAY BORCHERS, 2010, p. 148).

${ }^{33}$ [...] contemplar cualidades abstractas de los hombres (por ejemplo, la nacionalidad, el domicilio, la residencia, la pertenencia a un país por medio de la prestación de servicios, etc.) (GOLDSCHMIDT, 2009, p. 204).

${ }^{34}[. .$.$] refirieren a objetos (como, verbigracia, la situación de inmuebles y de muebles, el lugar$ de inmatriculación de un buque, una aeronave, un automotor, la propiedad intelectual, etc.) (GOLDSCHMIDT, 2009, p. 204).
} 
destino, acordo das partes referente ao Direito aplicável a um contrato)"35 (GOLDSCHMIDT, 2009, p. 204 - tradução livre).

É, pois, nos pontos de conexão que versam sobre acontecimentos que se funda a análise do tema proposto, é neles que se assentam os conflitos quanto ao Direito aplicável em matéria de contratos internacionais. Notadamente, dois destes pontos de conexão versam sobre a matéria: a autonomia das partes, o local de celebração de um contrato, e o local de execução deste negócio jurídico.

A autonomia da vontade confunde-se, no seu estudo, quando versada, concomitantemente, pelo Direito Privado doméstico e pelo Direito Privado Internacional. Naquele, "ela supõe que o Direito aplicável seja indubitavelmente o Direito privado próprio, ou seja, que se trate de um contrato absolutamente nacional"36 (GOLDSCHMIDT, 2009, p. 273). Ademais, entre Direito Privado e Direito Internacional Privado não pode haver muitas diferenças quando se versa sobre um mesmo instituto, vez que este pertence àquele.

O instituto da autonomia da vontade está presente nos dois ramos jurídicos e compreende a autonomia conflitual e a autonomia material, na concepção de Werner Goldschmidt. Àquela, "se entende por autonomia conflitual o direito das partes de eleger por declaração de vontade o Direito aplicável ao contrato"37 (GOLDSCHMIDT, 2009, p. 273 - tradução livre). Tratase de uma autonomia imprópria quando as partes elegem o Direito pleiteado.

O local de celebração do contrato, outro ponto de conexão que, em está presente em muitos ordenamentos jurídicos e, clama a si o requisito da formalidade exigida aos negócios jurídicos ou ato jurídico ${ }^{38}$, como versado em alguns Estados. Nesta matéria, Konrad Zweigert e Hein Kötz asseveram que "em todos os sistemas jurídicos modernos há negociações que devem ser

\footnotetext{
${ }^{35}$ [...] sucesos (como, por ejemplo, el lugar de la celebración o del cumplimiento de un contrato, puerto de salida o de destino, acuerdo de las partes referentes al Derecho aplicable a un contrato) (GOLDSCHMIDT, 2009, p. 204).

${ }^{36}$ Ella supone que el Derecho aplicable sea indudablemente el Derecho Privado propio, o sea, que se trate de un contrato absolutamente nacional (GOLDSCHMIDT, 2009, p. 273).

${ }^{37}$ Se entiende por autonomía conflictual el derecho de las partes a elegir por declaración de voluntad el Derecho aplicable al contrato (GOLDSCHMIDT, 2009, p. 273).

${ }^{38}$ Os Estados que compactuam o common law desconhecem a doutrina do negócio jurídico, advogada, notadamente, por Oskar von Bülow, na doutrina alemã, e, adotada pela legislação e doutrina brasileira.
} 
concluídas em uma forma especial se querem receber o reconhecimento jurídico" (1998, p. 366 - tradução livre).

O local de execução do contrato, outro ponto de conexão referido a um acontecimento, estabelece o Direito aplicável como o do local onde se deva adimplir a obrigação. É o "local no qual uma promessa dever ser cumprida, tanto por previsão específica ou pela interpretação da linguagem da promessa"39 (BLACK'S LAW DICTIONARY, 2009, p. 1266 - tradução livre).

Em matéria de contratos internacionais, a regulamentação da aplicação e escolha do Direito, através pontos de conexão, dá-se pelos tratados internacionais. São os idiomas do debate entre os Estados em matéria de conflitos de leis em contratos. No cenário geográfico delimitado, há vários tratados que versam sobre a matéria.

As Conferências de Haia, em matéria de Direito Privado, em atividade desde 1893, é um grande exemplo das tratativas, do diálogo entre os Estados nesta matéria. Esta "Conferencia gerou nada mais que trinta e nove Convenções de Haia em uma variedade de questões, variando de escolha do direito à jurisdição e de processo civil a reconhecimento de julgamentos"40 (REIMANN, 2008, p. 1378 - tradução livre).

A UNCITRAL, Comissão das Nações Unidas para o Direito do Comércio Internacional (United Nations Comission on International trade Law), criada pela Resolução n.을 2205 (XXI), de 17 de dezembro de 1966, pela Assembléia Geral, tem como função a harmonização e modernização das normas referentes ao seu objeto. A Convenção das Nações Unidas sobre Contratos Internacionais para a Venda de Bens requer o reconhecimento da autonomia conflitual, por exemplo, vez que é utilizada como fundamento normativo aos contratos. Conforme seu Art. 4ํㅡ, a Convenção aplica-se "somente a formação

\footnotetext{
${ }^{39}$ The place where a promise is to be performed, either by specific provision or by interpretation of the language of the promise (BLACK'S LAW DICTIONARY, 2009, p. 1266).

${ }^{40}[\ldots]$ conference has so far generated thirty-nine Hague Conventions on a large variety of issues, ranging from choice of law to jurisdiction and from civil procedure to judgments recognition (REIMANN, 2008, p. 1378).
} 
do contrato de venda e os direitos e obrigações do vendedor e comprador advindos do contrato" ${ }^{41}$ (UNCITRAL, 2010, p.1).

O Código de Bustamante representa uma codificação uniforme em matéria de Direito Internacional Privado, firmados por Peru, Uruguai, Panamá, Equador, México, Bolívia, Venezuela, Colômbia, Honduras, Costa Rica, Chile, Brasil, Argentina, Paraguai, Haiti, República Dominicana, Estados Unidos e Cuba, prevê, em seu Art. 180 que se aplica, "simultaneamente a lei do lugar do contrato e a da sua execução, à necessidade de outorgar escriptura ou documento público para a efficacia de determinados convenios e á de os fazer constar por escripto" (BRASIL, 1928, p. 1).

Estes tratados internacionais, analisados segundo Estados Unidos e Brasil, a aplicação é condicionada ao tratamento que Ihes conferem, é dizer, a adoção ou não das doutrinas monista e internacionalista de Direito Internacional Público. Ademais, naqueles, notadamente, cabe a qualificação do tratado em um tratado que se possa executar automaticamente, uma vez ratificado (self-executing agreement) ou se depende de ato normativo que o internalize e Ihe conceda eficácia (non self-executing).

Na União Europeia, exemplo exitoso do processo de integração regional no globo, há a filosofia inerente de unificar o que antes fora fragmentado. Unem-se os indivíduos na criação de uma cultura comunitária, a comunicação no seu livre acesso, e, derrubam-se as fronteiras físicas que dividem os Estados, facilitando a entrada e saída dos nacionais dos Estados membros. Esta filosofia unificadora permeia, também, o Direito. Ademais da criação de um Direito Comunitário, busca-se a unificação, ou mesmo harmonização do Direito Privado, e, logo, do Direito Internacional Privado.

A "europização", neste sentido, como assevera Mathias Reimann, manifesta-se sob dois conceitos. Pelo primeiro, "ela pode significar uma agenda acadêmica e educacional que visa à harmonização gradual do direito entre os países da Europa (com a legislação, por acaso, seguindo o

\footnotetext{
${ }^{41}[\ldots]$ only to the formation of the contract of sale and the rights and obligations of the seller and the buyer arising from such a contract (UNCITRAL)
} 
processo)"42 (2008, p. 1389 - tradução livre). O segundo conceito versa, conforme as lições do autor, em "significar que o direito nacional é prescrito, ou mesmo deslocado, pelo direito da União Europeia; este essencialmente opera do topo para baixo" ${ }^{\text {"43 }}$ (2008, p. 1389 - tradução livre). Embora esta seja a tendência atual, em sede de Direito Internacional Privado, pouco se tem unificado.

O Tratado de Amsterdã, de 1999, emendado pelo Tratado da Comunidade Europeia, em seus Art. 61 e 65, confere a Comunidade Europeia competência para disciplinar o Direito Internacional Privado, notadamente, o conflito de leis no espaço. Tal competência encontra-se na versão consolidada do Tratado da União Europeia, no Art. 65, b, segundo o qual, o bloco deve "promover a compatibilidade das normas aplicáveis nos Estados-Membros em matéria de conflitos de leis e de jurisdição" (UNIÃO EUROPEIA, 2006, p. 1). Em matéria contratual, todavia, os esforços unificadores são doutrinários, merecendo menção os estudos da comissão criada por Ole Lando.

Neste sentido, o diálogo havido entre União Europeia os Estados que a compõem, os Estados Unidos e Brasil, dá-se por meio de tratados internacionais, muitos dos quais multilaterais, como os elaborados e postos a acessão estatal, da UNCITRAL e da Conferência de Haia, ou entre Estados Unidos e Brasil os elaborados pela Conferência de Direito Privado da Organização dos Estados Americanos.

\section{DIMENSÃO DIKELÓGICA}

A justiça, "para Goldschmidt é um norte para a arbitragem dos valores, pois se trata de um valor absoluto"44 (ZANNETTI, 2009, p. XXVII - tradução livre). Em semelhante acepção manifesta-se Vicente Marotta Rangel, que a

\footnotetext{
${ }^{42}[\ldots]$ it can mean an academic and educational agenda aiming at the gradual harmonization of law among countries of Europe (with legislation perhaps following suit) (REIMANN, 2008, p. 1389).

${ }^{43}[\ldots .$.$] mean that national law is being prescribed, or even displaced, by European Union law;$ this essentially works from the top down (REIMANN, 2008, p. 1389).

${ }^{44}$ [...] para Goldschmidt es un norte para el arbitraje de los valores, pues se trata de un valor absoluto (ZENNETI, 2009, p. XXVII).
} 
descreve como "um valor transcendental, que remanesce incólume, fascinante, sedutora imutável", o que evolui, nas suas palavras, "são as instituições que, no curso dos séculos, almejam constantemente alcançá-la e pô-la a serviço do ser humano, de povos, de governos" (2007, p. 100). Este instituto pertence à dimensão dikelógica, nominada por Wener Goldschmidt devido a "uma deusa grega menor, Diké, não precisamente porque a justiça fora o valor menor no direito, mas porque requer para sua realização do concurso dos valores naturais e relativos o qual obstaculiza sua concretização" ${ }^{\text {"Z }}$ (ZANNETI, 2009, p. XXVII - tradução livre). É, neste sentido, 'impensável realizar justiça sem um mínimo de valores relativos" ${ }^{46}$ (ZANETTI, 2009, p. XXVII - tradução livre).

$O$ debate entre os entes que estão compreendidos na delimitação geográfica proposta deve ser orientada à justiça, a não sobreposição de interesses individuais fundados no uso, errôneo, de atributos econômicos, culturais, militares ou políticos. O diálogo orientado para a formação de tratados internacionais em sede de normas conflituais sobre contratos deve-se dar pautado na igualdade dos Estados participantes, e, considerando-se as diferenças que portam nos ordenamentos jurídicos pátrios.

Os Estados, através do processo legislativo, independentemente da processualística técnica que ostentam, miram-se por meio do Direito Comparado nos resultados e experiências de outros Estados na resolução de problemas comuns. A solução alcançada por um Estado em sede de conflitos de leis em matéria contratual, por exemplo, pode ser incorporada, transplantada por um outro Estado que detém igual dificuldade. Trata-se de um meio racional do emprego do Direito Comparado, e, em geralmente não prescinde de negociações para a formação de tratados internacionais. Outras vezes, essa ilação pode mobilizar as tratativas e concluir-se um acordo internacional que busque a incorporação de preceitos normativos comuns.

Da equidade da incorporação ou transplante de preceitos normativos, necessita-se conhecer, acerca do instituto espelhado, "se ele se provou

\footnotetext{
${ }^{45}[\ldots]$ una diosa griega menor, Diké, no precisamente porque la justicia fuera el valor menor em el derecho sino porque requiere para su realización del concurso de los valores naturales y relativos lo cual obstaculizan llevarla a cabo (ZANNETI, 2009, p. XXVII).

${ }^{46}[. .$.$] impensable realizar justicia sin un mínimo de valores relativos (ZANETTI, 2009, p. XXVII).$
} 
satisfatório no seu país de origem, e, em segundo, se irá funcionar no país onde é proposto que o adote. Pode ser que se prove impossível a adoção de qualquer modo, sem modificação" ${ }^{\text {47 }}$ (ZWEIGERT, KÖTZ, 1998, p. 17 tradução livre). Modificações ou adaptações são por vezes necessárias, e demonstram o respeito à cultura jurídica de cada Estado.

Do transplante ou incorporação orienta-se a unificação, uniformização e harmonização dos Direitos, ou fragmentos destes, todos termos que expressam conceitos distintos. O Direito uniforme, alcançado por meios espontâneos manifesta-se "quando coincidem os direitos primários de dois ou mais ordenamentos, seja natural e casualmente, seja porque têm a mesma origem, ou porque sofreram influências idênticas, ou, ainda, quando países adotam sistemas jurídicos clássicos" (DOLINGER, 2008, p. 31). É, pois, "resultante da natural coincidência de legislações influenciadas pelos mesmos fatores ou da iniciativa unilateral de um |Estado de seguir as normas do direito positivo de outro" (DOLINGER, 2008, p. 32).

O Direito uniformizado por direção, ao contrário daquela acima exposta, "resulta de esforço comum de dois ou mais Estados no sentido de uniformizar certas instituições jurídicas, geralmente por causa de sua natureza internacional" (DOLINGER, 2008, p. 33). Alcança-o por meio de tratados internacionais nas matérias propostas à unificação.

A unificação, seja por método espontâneo ou dirigido, não importará na extinção do conflito, do problema objeto do Direito Internacional Privado, mas na igualdade de tratamento que os Estados conferem a determinadas matérias. O problema internacional continuará devendo o respeito ao elemento estrangeiro, que caracteriza sua atuação. Inserido em blocos regionais, todavia, vez unificado todo o Direito Internacional Privado, ao menos sua vocação de conflitos de leis, inaugurar-se-ia um novo Direito Internacional Privado, na União Europeia, um Direito Internacional Privado europeu. $O$ problema conflitual que reclama uma solução por este ramo jurídico, não, mas,

\footnotetext{
${ }^{47}[\ldots]$ whether it has proved satisfactory in its country of origin, and secondly, whether it will work in the country where it is proposed to adopt it. It may well prove impossible to adopt, at any rate without modification (ZWEIGERT, KÖTZ, 1998, p. 17).
} 
se basearia em indicações de pontos de conexões alemãs, franceses, ingleses ou espanhóis, mas num ponto de conexão europeu.

A unificação é justa se observam as diferenças entre os ordenamentos jurídicos dos Estados que a pleiteiam. Na unificação espontânea, o critério justo reside na atenção dos legisladores pátrios na análise da pertinência ou não da adoção de determinada instituição jurídica ao seu ordenamento e aos nacionais. A unificação dirigida, além daquelas imposições mencionadas à espontânea, deverá respeito aos demais ordenamentos jurídicos dos Estados que almejam a unificação. A tolerância e a cautela devem ser exercitadas sempre na busca da unificação jurídica.

Dos pontos de conexões explanados neste artigo, deve-se analisá-los, também, sob os paradigmas do justo, da dimensão dikelógica. Da autonomia da vontade, Werner Goldschmidt aduz que:

é muitas vezes tão difícil ao legislador encontrar em casos absolutamente internacionais o Direito que seria insensato não permitir às partes que o determinassem, não conhecendo nunca ninguém um assunto que os próprios interessados ${ }^{48}(2009$, p. $309-$ tradução livre).

Nota-se, mais uma vez, a importância e verossimilhança do dístico de Henry S. Maine de que "o movimento das sociedades progressistas tem, até agora, sido um movimento do status ao contrato" ${ }^{49}$ (apud ZWEIGERT, KÖTZ, 1998, p. 325 - tradução livre). Garante-se a liberdade de escolha do Direito aplicável àqueles que interessam o negócio jurídico celebrado. Ademais, "a eleição do Direito aplicável não está limitada pela ordem pública, pois a eleição como tal, nunca pode ferir os princípios básicos de nossa convivência" ${ }^{50}$ (GOLDSCHMIDT, 2009, p. 310 - tradução livre).Apenas o Direito elegido

\footnotetext{
48 Es muchas veces tan difícil para el legislador encontrar en casos absolutamente internacionales el Derecho aplicable que sería insensato no permitir a las partes que lo determinaran, no conociendo nunca nadie mejor un asunto que los propios interesados (GOLDSCHMIDT, 2009, p. 309).

${ }^{49}[\ldots]$ the movement of the progressive societies has hitherto been a movement from Status to Contract (MAINE apud ZWEIGERT, KÖTZ, 1998, p. 325).

${ }^{50}$ La elección del Derecho aplicable no está limitada por el orden público, pues la elección como tal, nunca puede conculcar los principios básicos de nuestra convivencia (GOLDSCHMIDT, 2009, p. 310).
} 
poderá ferir a concepção, doméstica e internacional, de ordem pública, não o mero direito subjetivo à eleição.

O ponto de conexão local de celebração funda-se na exigência de determinadas formas procedimentais, entretanto, "do que precede pode-se desprender do império da regra lócus regit actum sobre as formas somente deve ser facultativo" 51 , ademais, "os interessados devem poder igualmente acudirem-se às formas previstas na lei que rege o fundo do negócio"52 (GOLDSCHMIDT, 2009, p. 313 - tradução livre). O contrato é um instituto de Direito Privado, fundado na preponderância de uma filosofia individualista, e, portanto, a prescrição de formas não devem dificultar sua conclusão. A formalidade excessiva transcende a justiça.

Do ponto de conexão local do adimplemento da obrigação contratual, menciona-se que "a validez intrínseca dos contratos, ao contrário, não se deve governar normalmente pela lei do lugar da celebração do contrato" ${ }^{33}$, vez que "um contrato tem, em princípio, sua sede, seu centro de gravidade no país de sua execução; é a lei do país da execução a que deve imperar sobre sua validez intrínseca e seus efeitos" ${ }^{44}$ (GOLDSCHMIDT, 2009, p. 313 - tradução livre). O critério correto, pautado na justiça, reside na orientação da lei do local da execução, quando assim for adotado como ponto de conexão pelo Estado ou pelo tratado internacional, vez que é neste local onde todos os efeitos do contrato manifestar-se-ão, não no seu local de celebração. Este é apenas o ponto de idealização de seus efeitos e não merece chamar a si a disciplina do instrumento jurídico.

Ressalta-se, por fim, a importância do respeito mútuo entre os Estados no debate em prol à unificação, espontânea ou dirigida, das matérias de Direito Internacional Privado, voltadas aos conflitos de leis em contratos

\footnotetext{
${ }^{51}$ De lo que precede se puede desprender que el imperio de la regla lócus regit actum sobre las formas sólo debe ser facultativo (GOLDSCHMIDT, 2009, 313).

${ }^{52}$ Los interesados deben poder igualmente acudir a las formas previstas en la ley que rige el fondo del negocio (GOLDSCHMIDT, 2009, p. 313).

${ }^{53} \mathrm{La}$ validez intrínseca de los contratos, al contrario, no se debe gobernar normalmente por la ley del lugar de la celebración del contrato (GOLDSCHMIDT, 2009, p. 313).

${ }^{54}$ Un contrato tiene, en principio, su sede, su centro de gravitad en el país de su ejecución, es la ley del país de la ejecución la que debe imperar sobre su validez intrínseca y sus efectos (GOLDSCHMIDT, 2009, p. 313).
} 
internacionais. Pautar-se-á na tolerância e zelo pelas diferenças entre os ordenamentos jurídicos que pertencem aos Estados. O Direito Internacional Privado, é, por natureza, como expresso na obra de Werner Goldschmidt, o Direito da tolerância, por "basear-se no respeito ao elemento estrangeiro; e o respeito, por sua vez, consiste em fazer com o caso o que presumivelmente com ele fariam no país a que pertence" ${ }^{\prime 5}$ (GOLDSCHMIDT, 2009, p13 tradução livre). A unificação e adoção de parâmetros equânimes em se tratando de pontos de conexão que versem sobre contratos internacionais, não devem nunca erguer obstáculos à aplicação do Direito estrangeiro, do elemento alienígena. $O$ debate justo funda-se na igualdade de tratamento entre seus participantes, no respeito às diferenças nas suas instituições jurídicas, e, na observância da utilidade da unificação aos indivíduos.

\section{CONCLUSÃO}

Do exposto, o debate, o diálogo funda o Direito. É nele que se manifesta o processo, tanto da prestação da tutela jurisdicional, das tratativas do Poder Executivo na busca da formação de instrumentos internacionais, quanto no processo legiferrante. Por tratar-se da esfera jurídica, todavia, este debate deve ser orientado por medidas justas, na sua consecução, assim como no seu resultado. A concepção trialista do Direito, ora utilizada, e, idealizada por Werner Goldschmidt, auxilia a percepção completa da sua utilidade: o debate volta-se a fatos oriundos do âmbito concreto, vivenciado por instituições e indivíduos, que importam ao Direito; do debate em prol da tutela destes fatos surgem as normas, que, por sua vez devem objetivar um valor, a justiça.

Os processos de unificação, espontânea ou dirigida, do Direito Privado ocorrem de forma fragmentada, vez que se elegem matérias individuais para esta tarefa. Trata-se de um meio acertado, vez que, quando dispostas com o auxilio do Direito Comparado, permite-se a análise das diferenças e

\footnotetext{
${ }^{55}$ [...] basarse en el respeto al elemento extranjero; y el respeto, a su vez, consiste en hacer con el caso lo que presumiblemente con él harían en el país al que pertenece (GOLDSCHMIDT, 2009, p. 13).
} 
semelhanças, assim como, o respeito a estas. Não se pode nunca impor a unificação de instituições jurídicas.

Em sede de conflitos de leis em matéria contratual internacional, o diálogo unificador entre os Estados funda-se na adoção comum de pontos de conexão, como acima mencionados: a autonomia da vontade, o local de celebração do negócio e o local de execução. Cada um confere determinados graus de justiça às partes contraentes, e, devem ser adotadas pelos Estados com a máxima cautela. Autorizar a ampla autonomia da vontade, a autonomia conflitual, não demonstra a justiça suficiente, vez que há contratos que merecem maior proteção estatal quanto ao Direito elegido, como os contratos de seguro. Em oposição restringir a eleição do Direito aplicável quanto ao local de celebração ou ao local de execução, também não se mostra arrazoado.

Neste sentido, busca-se o equilíbrio, o debate fundado em condições equânimes, e, o respeito às diferenças entre os ordenamentos jurídicos dos Estados na consecução de tratados que versem sobre a unificação do Direito Internacional Privado em matéria de contratos internacionais. A unificação, como restou demonstrado, não importa o fim do conflito, objeto daquele ramo do Direito, mas no seu tratamento igual, no surgimento de um Direito Internacional privado fundado no respeito mútuo entre os seus criadores. É possível o diálogo comum entre União Europeia, Estados Unidos e Brasil, em sede de conflitos de leis em matéria contratual internacional, quando voltados e resultados justos, fundados no respeito às diferenças jurídicas.

\section{REFRÊNCIAS}

BLACK'S LAW DICTIONARY. Ed. GARNER, Bryan A. Estados Unidos: West, 2009.

BRASIL. Convenção de Direito Internacional Privado. Aprovada pelo Decreto Legislativo5.647, de 08.01.1929. Promulgada pelo Decreto 18.871, de 13.08.1929.

DOLINGER, Jacob. Direito Internacional Privado. Parte Geral. 9. Ed. Rio de Janeiro: Renovar, 2008. 
FAUVARQUE-COSSON, Bénédicte. Development of Comparative Law in France. In: ZIMMERMANN, Reihard; REIMANN, Mathias. The Oxford Handbook of Comparative Law. Nova lorque: Oxford University Press, 2008.

GELDART, William. Introduction to English Law. Revisado por YARDLEY, Sir David. 11. Ed. Nova lorque: Oxford University Press, 1995.

GOLDSCHMIDT, Werner. Derecho Internacional Privado. Derecho de la Tolerancia. 10. Ed. Buenos Aires: Editorial Abeledo Perrot, 2009.

GROTIUS, Hugo. The Rights of War and Peace. Vol. I. Trad. Richard Tuck e Knud Haakonsen. Indianápolis-EUA: Liberty Fund.

JANSEN, Nils. Comparative Law and Comparative Knowledge. In: ZIMMERMANN, Reihard; REIMANN, Mathias. The Oxford Handbook of Comparative Law. Nova lorque: Oxford University Press, 2008.

MICHAELS, Ralf. The Functional Method of Comparative Law. In: ZIMMERMANN, Reihard; REIMANN, Mathias. The Oxford Handbook of Comparative Law. Nova lorque: Oxford University Press, 2008.

REIMANN, Mathias. Comparative Law and Private International Law. In: ZIMMERMANN, Reihard; REIMANN, Mathias. The Oxford Handbook of Comparative Law. Nova lorque: Oxford University Press, 2008.

SYMEONIDES, Symeon C., BORCHERS, Ptarick J., HAY, Peter. Conflict of Laws. 5. Ed. Estados Unidos: West, 2010.

UNCITRAL. United Nations Conventions on Contracts for the International Sale of Goods. Viena: Uncitral, 2010.

UNIÃO EUROPEIA. Versões Consolidadas do Tratado da União Europeia e do Tratado que institui a Comunidade Europeia. In: Jornal Oficial da União Europeia, 29. Dez. 2006. Disponível em: <www.coe.int> Acesso em 28 set. 2011.

ZWEIGERT, Konrad; KÖTZ, Hein. An Introduction to Comparative Law. Nova lorque: Oxford University Press, 1998.

Recebido para publicação: 22/03/2012

Aceito para publicação: 09/08/2012 